\title{
Avaliação da sustentabilidade ambiental da sede administrativa de uma instituição federal - Rio de Janeiro, Brasil
}

\author{
Igor Laguna Vieira'; Elmo Rodrigues da Silva'; Elisete Dahmer Pfitscher ${ }^{2}$ \\ igor_laguna@hotmail.com
}

1. Universidade do Estado do Rio de Janeiro - UERJ 2. Universidade Federal de Santa Catarina - UFSC

Histórico do Artigo:

Recebido em: 20 de março de 2018 Aceito em: 06 de junho de 2018 Publicado em: 28 de dezembro de 2018

Resumo: Considerando-se a importância do setor governamental brasileiro em relação à sustentabilidade socioambiental, questiona-se como tal setor tem contribuido nesse sentido. Este artigo apresenta os resultados da avaliação da sustentabilidade ambiental da sede administrativa de uma autarquia federal localizada no município do Rio de Janeiro. A abordagem metodológica da pesquisa é qualitativa e descritiva. Na coleta de dados, utilizou-se do estudo de caso com aplicação de questionários dirigidos aos gestores do órgão e observações in loco. 0 Sistema Contábil Gerencial Ambiental (SICOGEA - geração 2), desenvolvido por pesquisadores da Universidade Federal de Santa Catarina, foi selecionado como método avaliativo. Esse método possui 124 questões distribuídas em quatro áreas: produção; recursos humanos; marketing e finanças, que possuem valoração qualitativa em escala variando de zero a cinco, podendo-se atribuir pesos às mesmas, a critério do pesquisador. Na autarquia estudada, obteve-se um índice geral de sustentabilidade ambiental de 43,19\%, conceito "regular" pelo SICOGEA. Entre as quatro áreas do método, a de produção foi a que atingiu o valor mais baixo, de 22,12\%, considerado "fraco". Conclui-se haver deficiências na gestão ambiental da organização. Ela deve instituir práticas sustentáveis visando minimizar ou evitar os impactos ambientais negativos oriundos de suas atividades. Uma das limitações do método SICOGEA é que ele possibilita a subjetividade do pesquisador, devido à falta de padronização da lista de verificação, bem como dificulta a comparação dos resultados entre instituições que atuam numa mesma atividade. Para trabalhos futuros sugere-se aplicar o método SICOGEA em outros órgãos públicos, a fim de propor melhorias ao sistema.

Palavras-chave: Contabilidade Ambiental, Sistemas de Gestão Ambiental, Sustentabilidade, Gestão Pública.

\section{Evaluation of the environmental sustainability of the administrative office of a federal institution - Rio de Janeiro, Brazil}

\begin{abstract}
Considering the importance of the Brazilian governmental sector in relation to socio-environmental sustainability, it is important to question how such sector has contributed in this respect. This article presents the results of the environmental sustainability evaluation of the administrative headquarters of a federal autarky located in the city of Rio de Janeiro. The methodology approach is a qualitative and descriptive research. In the data collection, the case study was used with the application of questionnaires directed to the managers of the autarky, complemented by on-site observations. The Environmental Management Accounting System (SICOGEA generation 2), developed by researchers from the Federal University of Santa Catarina, was selected as the evaluation method. This method has 124 questions distributed in four areas: production; human Resources; marketing and finance, with a qualitative valuation in scale ranging from zero to five, weights can be attributed to them, at the discretion of the researcher. In the studied autarky, the general environmental sustainability index obtained was $43.19 \%$, a "regular" concept by SICOGEA. Among the four areas of the method, the production area obtained the lowest rate, $22.12 \%$, considered "weak". It is concluded that there are deficiencies in the environmental management of the organization and it must institute more sustainable practices in order to minimize or avoid negative impacts arising from its activities. One of the limitations of the SICOGEA method is that due to the lack of standardization of the checklist, there is an open space for the subjectivity of the researcher, it also makes it difficult to compare the results between institutions working in the same activity. For future works it is suggested to apply the SICOGEA method in other public agencies, in order to propose improvements.

Keywords: Environmental Accounting, Environmental Management Systems, Sustainability, Public Administration.
\end{abstract}




\title{
Evaluación de la sostenibilidad ambiental de la oficina administrativa de una institución federal - Rio de Janeiro, Brasil
}

\begin{abstract}
Resumen: Considerando la importancia del gobierno brasileño con relación a la sostenibilidad socioambiental, se cuestiona cómo tal sector ha contribuido en ese sentido. Este artículo presenta los resultados de la evaluación de la sostenibilidad ambiental de la sede administrativa de una autarquía federal ubicada en el municipio de Río de Janeiro. El enfoque metodológico de la investigación es cualitativo y descriptivo. En la recolección de datos, se utilizó del estudio de caso con aplicación de cuestionarios dirigidos a los gestores del órgano, complementada por observaciones in situ. El Sistema Contable Gerencial Ambiental (SICOGEA - generación 2), desarrollado por investigadores de la Universidad Federal de Santa Catarina, fue seleccionado como método de evaluación. Este método tiene 124 temas distribuídos en cuatro áreas: producción; recursos humanos; Marketing y finanzas, com una valoración cualitativa en escala de cero a cinco, que permite la atribuicion de pesos a los mismos, a discreción del investigador. En la autarquía estudiada, se obtuvo un índice general de sostenibilidad ambiental del 43,19\%, concepto "regular" por el SICOGEA. Entre las cuatro áreas de le método, la producción alcanzó el valor más bajo, 22,12\%, considerado "débil". Se concluye que hay deficiencias en la gestión ambiental de la organización y que la misma debe instituir prácticas más sostenibles para minimizar o evitar impactos negativos oriundos de sus actividades. Una de las limitaciones del método SICOGEA es que posibilita la subjetividad del investigador, debido a la falta de estandarización de la lista de verificación, como también dificulta la comparación de los resultados entre instituciones que actúan en una misma actividad. Para trabajos futuros se sugiere aplicar el método SICOGEA en otros organismos públicos, a fin de proponer mejoras.
\end{abstract}

Palabras clave: Contabilidad Ambiental, Sistemas de Gestión Ambiental, Sostenibilidad, Gestión Pública.

\section{INTRODUÇÃO}

0 sistema capitalista industrial de matriz desenvolvimentista, em seu processo produtivo, utiliza intensivamente recursos naturais e fontes de energia não renováveis, como 0 petróleo, e tem contribuído com a redução da biodiversidade, com o aumento da poluição e com as mudanças climáticas de proporções globais, comprometendo assim a sustentabilidade ambiental, como já vem ocorrendo em diversas regiões do planeta (SILVA, 2014).

As organizações, sejam elas públicas ou privadas, possuem um papel importante e têm responsabilidades na busca pela sustentabilidade socioambiental. Algumas instituições, ao adotarem a gestão ambiental e o emprego de tecnologias ambientais, conseguem aproveitar melhor seus recursos do que outras que não o fazem. Portanto, elas podem se tornar mais competitivas ao diminuir o desperdício de recursos naturais e financeiros, bem como ao evitar ou minimizar danos ao meio ambiente. Além disso, elas buscam a conformidade legal, reduzindo o risco de haver penalidades ou passivos ambientais (TAUCHEN; BRANDLI, 2006).

Segundo Guthrie e Parker (1989), as organizações são legitimadas baseando-se no fato de que operam na sociedade por meio de um contrato social. À luz da teoria da legitimidade, é fundamental o papel dos gestores em perceber como a organização é vista pela sociedade. De alguma forma as práticas organizacionais podem estar rompendo com esse contrato social, 
carecendo de estratégias de correção que deverão ser divulgadas a fim de mudar a percepção da sociedade (DEEGAN, 2002). Dessa forma, estratégias de divulgação podem inclusive reverter um quadro negativo da organização, ou ao menos amenizá-lo, perante aos seus interessados. Portanto, é de suma importância evidenciar uma imagem positiva, utilizando de forma correta as estratégias de legitimação.

Nessa perspectiva, a Contabilidade Ambiental objetiva mensurar a relação entre empresa e meio ambiente, gerando informações que contribuam com o processo decisório da gestão ambiental, além de permitir maior fiscalização, controle das atividades produtivas e publicidade das ações (SOUZA et al., 2015).

Entende-se por Contabilidade Ambiental pelo:

"estudo do patrimônio ambiental (bens, direitos e obrigações ambientais) das entidades, cujo objetivo é fornecer informações sobre os eventos ambientais que causam modificações na situação patrimonial, bem como realizar sua identificação, mensuração e evidenciação” (SANTOS et al., 2001, p.90).

Essas informações vão:

"desde os investimentos realizados, seja em nível de aquisição de bens permanentes de proteção a danos ecológicos, de despesas de manutenção ou correção de efeitos ambientais do exercício em curso, de obrigações contraídas em prol do meio ambiente, e até de medidas físicas, quantitativas e qualitativas, empreendidas para sua recuperação e preservação" (MARTINS; DE LUCA,1994, p.25).

Nesse sentido, na Universidade Federal de Santa Catarina (UFSC) foi proposto o Sistema Contábil Gerencial Ambiental (SICOGEA) por Pfitscher (2004), a partir do método de Gerenciamento de Aspectos e Impactos Ambientais (GAIA) formulado por Lerípio (2001) em sua tese de doutoramento nessa Universidade. 0 objetivo desse último foi de sensibilizar os administradores e colaboradores para avaliar o desempenho e o planejamento ambiental das organizações produtivas baseados na prevenção da poluição.

Uma das proposições feitas pelo SICOGEA, complementando o método GAIA, foi de incluir a Contabilidade Ambiental, a fim de analisar a sustentabilidade nas organizações. A intenção dessa inclusão contábil, que não existia no método GAIA, foi de valorizar as percepções e atitudes ambientais dos gestores das organizações.

Com o auxílio do método SICOGEA, a organização pode contribuir com a sustentabilidade ambiental ao avaliar suas atividades em termos dos aspectos ambientais e impactos a eles associados. Ao incluir a contabilidade ambiental nesse sistema, é possível também se obter benefícios econômicos e socioambientais, como a redução de desperdícios e 
Avaliação da sustentabilidade ambiental da sede administrativa de uma instituição federal - Rio de Janeiro, Brasil

de gastos, bem como melhorar o controle e a prevenção da poluição (PFITSCHER, 2004). Além disso, outra intenção da autora do SICOGEA foi a de buscar a colaboração de diferentes universidades e centros de pesquisa, a fim de aprimorar essa ferramenta de uso público.

Nunes (2010) propôs adaptações e melhorias ao SICOGEA, obtendo a segunda geração do método. Uhlmann (2011), por sua vez, analisou o SICOGEA - geração 2, sugerindo aperfeiçoamentos nesse sistema, dando origem ao SICOGEA - geração 3.

Ainda a partir do SICOGEA, Freitas (2013) propôs o Modelo de Avaliação de Sustentabilidade Socioambiental (MASS) aplicado às Instituições de Ensino Públicas Federais (IFES). Boca Santa (2017) compôs o Modelo de Avaliação Gerencial para Edifício Sustentável (MAGESTAL) também a partir desse sistema.

No caso da busca do desenvolvimento sustentável pelo setor público, é necessária a atuação dos gestores, não somente na regulação e fiscalização, mas também atuando ativamente no processo de preservação do meio ambiente, assumindo um compromisso social e ambiental (CHAVES et al., 2013). 0 setor governamental deve ser proativo em relação às questões ambientais, por ser ele responsável pela política e controle ambiental no país.

Nesse sentido, os governos vêm implantando programas e projetos para incentivar os gestores públicos na utilização de práticas que estimulem a responsabilidade socioambiental no setor governamental. A Agenda Ambiental na Administração Pública (A3P), por exemplo, foi criada e desenvolvida pelo Ministério do Meio Ambiente (MMA) e visa à construção de uma nova cultura institucional voltada para uma gestão socioambiental mais responsável (BRASIL, 2009; MMA, 2018). A A3P é aplicável nas três esferas do governo (federal, estadual e municipal) e nos três poderes (executivo, legislativo e judiciário), sendo sua adesão voluntária por parte das organizações públicas.

Segundo MMA (2018), a A3P possui 15 (quinze) objetivos básicos, a saber: I - Apoiar os órgãos públicos na criação e implementação de ações de responsabilidade socioambiental; II Sensibilizar os servidores para a necessidade de preservação dos bens naturais; III - Estimular a construção de uma cultura institucional que agregue valores, atitudes e comportamentos consoantes com a responsabilidade socioambiental; IV - Incentivar os órgãos públicos a adotarem medidas que visem à redução de impactos socioambientais negativos decorrentes de suas atividades; V - Aumentar a eficiência da gestão, promovendo a economia de recursos naturais e de gastos institucionais; VI - Promover a atualização sistemática do conhecimento e a modernização de conceitos, instrumentos, tecnologias e metodologias, referentes ao campo da sustentabilidade; VII - Promover a transparência no serviço público; VIII - Garantir a 
acessibilidade nos órgãos públicos às pessoas portadoras de deficiência ou com mobilidade reduzida; IX - Estimular e apoiar ações de defesa do meio ambiente; X - Facilitar o acesso das instituições públicas ao Programa A3P; XI - Estimular ações de cooperativismo, solidariedade, respeito, compromisso profissional e ético; XII - Capacitar e sensibilizar os gestores públicos quanto à responsabilidade socioambiental; XIII - Colaborar para a melhoria da qualidade de vida dos servidores; XIV - Incentivar às ações coletivas e às decisões democráticas; e XV Promover a produção e o consumo sustentáveis.

Para o cumprimento de seus objetivos, a A3P foi estruturada em seis eixos temáticos, contendo fundamentos básicos, conforme mostrados no Quadro 1.

\section{Quadro 1 - Eixos Temáticos da A3P}

\begin{tabular}{|c|c|}
\hline Eixos Temáticos & $\begin{array}{ll}\text { Fundamentos } \\
\end{array}$ \\
\hline $\begin{array}{l}\text { Uso Racional dos Recursos } \\
\text { Naturais e Bens Públicos }\end{array}$ & $\begin{array}{l}\text { Utilizar energia, água, madeira, papel, copos e materiais de } \\
\text { expediente, entre outros, de forma racional, para que haja economia } \\
\text { dos recursos financeiros, menor desperdício e menor impacto } \\
\text { ambiental negativo. }\end{array}$ \\
\hline $\begin{array}{l}\text { Gestão Adequada dos Resíduos } \\
\text { Gerados }\end{array}$ & $\begin{array}{l}\text { Adotar a política dos 5R's - Repensar, Reduzir, Reutilizar, Reciclar e } \\
\text { Recusar - e, com base na Lei n }{ }^{\circ} 12.305 / 10 \text {, que estabelece a Política } \\
\text { Nacional de Resíduos Sólidos (PNRS), implantar o gerenciamento de } \\
\text { resíduos sólidos. }\end{array}$ \\
\hline $\begin{array}{l}\text { Qualidade de Vida no Ambiente } \\
\text { de Trabalho }\end{array}$ & $\begin{array}{l}\text { Criar meios para que todas as pessoas que circulam no ambiente se } \\
\text { sintam bem e, conforme cada caso, adotar procedimentos e instalar } \\
\text { equipamentos que contribuam para a melhor qualidade de vida. }\end{array}$ \\
\hline $\begin{array}{lll}\text { Sensibilização } & \text { e Capacitação } \\
\text { dos servidores } & & \end{array}$ & $\begin{array}{l}\text { Criar e consolidar nos servidores a consciência cidadã quanto à } \\
\text { responsabilidade socioambiental, com a adoção de práticas que } \\
\text { promovam a sustentabilidade e o respeito à vida. }\end{array}$ \\
\hline $\begin{array}{l}\text { Contratações } \\
\text { Sustentáveis }\end{array}$ & $\begin{array}{l}\text { Adquirir e contratar com critérios de sustentabilidade, e considerar a } \\
\text { relação custo/benefício no médio e longo prazos, e não somente o } \\
\text { critério de menor preço. }\end{array}$ \\
\hline Construções Sustentáveis & $\begin{array}{l}\text { Construir e/ou reformar considerando critérios que atendam o } \\
\text { conforto térmico e acústico, fazendo uso da luz solar, energia dos } \\
\text { ventos e água da chuva, utilizar materiais e equipamentos que } \\
\text { impliquem em maior economia de energia, entre outros, e produzam } \\
\text { pouco ou nenhum impacto ambiental; garantir a acessibilidade às } \\
\text { pessoas portadoras de deficiência ou com mobilidade reduzida. }\end{array}$ \\
\hline
\end{tabular}

Fonte: MMA (2018)

De acordo com o MMA (2018), são instrumentos da Agenda Ambiental na Administração Pública: I - Termo de Adesão; II - Parcerias institucionais; III - Rede A3P; IV - Certificado de Sustentabilidade e Selo A3P; V - Prêmio A3P - Melhores Práticas de Sustentabilidade; VI Fórum A3P; VII - Publicações ou outros meios de divulgação; VIII - Sistema de Responsabilidade Socioambiental - RESSOA. 
Avaliação da sustentabilidade ambiental da sede administrativa de uma instituição federal - Rio de Janeiro, Brasil

Cabe destacar que a Instrução Normativa nº 01 (MP0G, 2010), da administração pública federal, é voltada para a aquisição de bens e contratação de serviços e obras segundo critérios de sustentabilidade ambiental. Além dessa, o Decreto Federal nº 7.746/2012 (BRASIL, 2012) instituiu a exigência de programas de logística sustentável nos órgãos, vindo a corroborar para a disseminação de práticas ambientalmente adequadas.

Apesar da existência desses instrumentos, são ainda necessários avanços para que a administração pública racionalize seus gastos e desenvolva atividades gerenciais efetivas em prol da preservação do meio ambiente, conforme está previsto no artigo 225 da Constituição da República Federativa do Brasil (BRASIL, 1988).

Nesse contexto, obtém-se a pergunta norteadora da pesquisa: como uma instituição federal pode contribuir com a sustentabilidade ambiental na sua gestão? Assim, este artigo visa apresentar os resultados de um estudo qualitativo que teve como objetivo avaliar a sustentabilidade socioambiental na sede administrativa de uma autarquia federal, localizada no município do Rio de Janeiro. Para tal, o método SICOGEA (Geração 2) foi selecionado como referência para realizar a avaliação da sustentabilidade na instituição selecionada para 0 estudo, o qual foi também utilizado por Souza e Pfitscher (2013) e Barbosa (2014) em outros órgãos públicos, com essa mesma finalidade.

A relevância do tema está relacionada ao número representativo de órgãos e setores do serviço público no país que estão distribuídos nas três esferas governamentais: federal, estadual e municipal, consumindo uma elevada quantidade de materiais, bens, serviços, entre outros. Tal consumo associado ao uso de recursos naturais, a exemplo da água, derivados de petróleo e consumo de energia elétrica, além da produção de resíduos, efluentes e emissões, podem representar um impacto ambiental considerável, tendo em conta a extensão territorial e a biodiversidade do país.

De acordo com Böhringer e Jochem (2007), aquilo que não pode ser claramente medido dificilmente será aprimorado ou atingido. Portanto, o desenvolvimento e a aplicação de métodos para a avaliação da sustentabilidade têm um papel fundamental para se conhecer o desempenho econômico, social e ambiental de uma organização, seja ela pública ou privada, e auxiliar na tomada de decisão pelos seus gestores em prol do meio ambiente.

Nesse sentido, o trabalho realizado é também importante na medida que contribui com a disseminação do conceito de sustentabilidade ambiental no setor público e no aperfeiçoamento dessa ferramenta gerencial - o SICOGEA, a fim de proporcionar uma melhoria da gestão dessas organizações, a exemplo da autarquia federal que foi objeto desse estudo. 


\section{MATERIAL E MÉTODOS}

Este estudo pode ser classificado como descritivo, quanto aos objetivos; como pesquisa de campo, quanto às fontes de dados; e como estudo de caso, quanto aos procedimentos de coletas de dados. Já a sua abordagem é qualitativa (SANTOS, 2015).

Esta pesquisa foi desenvolvida na sede administrativa de uma autarquia federal, localizada no Rio de Janeiro/RJ. São dois edifícios localizados na mesma rua, com área total edificada de aproximadamente de nove mil $\mathrm{m}^{2}$, onde trabalham 354 servidores e 130 trabalhadores terceirizados (manutenção, limpeza, recepção e segurança). 0 órgão foi escolhido pelo fácil acesso às informações pelos pesquisadores.

A autarquia não elabora o balanço socioambiental, o que poderia contribuir na análise das ações ambientais praticadas pelo órgão. Outra observação importante é que esse órgão ainda não aderiu à A3P.

Para avaliar a sustentabilidade na autarquia foi utilizada uma lista de verificação baseada na proposta de Nunes (2010), quando do desenvolvimento do SICOGEA - geração 2. A lista possui 124 questões, que foram respondidas com o auxílio de sete gestores do órgão e verificações in loco. Esta pesquisa ocorreu no período de 10/03/2017 a 07/04/2017.

A pesquisa ocorreu em dois momentos. No primeiro, Vieira e Silva (2018) estudaram a mesma autarquia, porém utilizaram outro método: os autores elaboraram um checklist baseado na A3P, avaliando o grau de aderência do órgão às práticas sugeridas pela agenda. Para esse questionário, os mesmos optaram que as respostas variassem de 0 a 2 , sem a possibilidade de haver pesos variados para as questões.

A lista de verificação proposta por Nunes (2010) agrupa-se em quatro áreas, com um total de sete critérios, sendo eles mostrados no Quadro 1.

Quadro 1 - Áreas e critérios avaliados pelo SICOGEA

\begin{tabular}{|c|c|}
\hline ÁREA & CRITÉRIOS \\
\hline \multirow{2}{*}{ Produção } & Processos de Produção \\
\cline { 2 - 2 } & Fornecedores \\
\cline { 2 - 2 } & Manutenção \\
\cline { 2 - 2 } & Equipe de Colaboradores \\
\cline { 2 - 2 } Recursos Humanos & Gestão da Instituição \\
\hline Marketing & Responsabilidade Socioambiental \\
\hline Finanças & Contabilidade Gerencial e Auditoria \\
\hline
\end{tabular}

Fonte: adaptado de Nunes (2010) 
Avaliação da sustentabilidade ambiental da sede administrativa de uma instituição federal - Rio de Janeiro, Brasil

De acordo com o SICOGEA (geração 2), as respostas possuem uma valoração que varia de 0 (zero) a 5 (cinco) para cada uma das 124 questões formuladas, a saber: 0 (zero) - para itens em que não se demonstra nenhum investimento/controle sobre o tema avaliado; 1(um) para itens em que se demonstra algum investimento/controle sobre o tema avaliado; 2 (dois) para itens em que se demonstra investimento/controle um pouco maior que o item anterior sobre o tema avaliado; 3 (três) - para itens em que se demonstra investimento/controle um pouco maior que o item anterior sobre o tema avaliado; 4 (quatro) - para itens em que se demonstra investimento/controle quase que total sobre o tema avaliado e; 5 (cinco) - para itens em que se demonstra investimento/controle total sobre o tema avaliado; NA - Não se Aplica, para os itens em que não se atribui a possibilidade de haver questionamentos que enquadrariam na entidade pesquisada.

É possível também atribuir pesos para cada questão (pontos possíveis), ficando esses pesos a critério do pesquisador, que não devem ser divulgados ao respondente.

No caso da pesquisa atual, os autores atribuíram o peso 2 (dois) para as questões que estão diretamente ligadas aos eixos e objetivos presentes na cartilha da Agenda Ambiental da Administração pública - A3P (BRASIL, 2009; MMA, 2018). Por “diretamente” entende-se aqueles questionamentos cujo tema está dentro dos objetivos da A3P. Já para as questões que não foram explicitamente tratadas em tal cartilha foi atribuído o peso 1 (um).

Para calcular a sustentabilidade ambiental utilizou-se a seguinte fórmula, conforme proposição do método SICOGEA: Índice geral de sustentabilidade = pontos alcançados/pontos possíveis. Os pontos alcançados são obtidos pelo somatório da "nota" de cada questão dada pelo respondente multiplicada pelo seu peso. Já os pontos possíveis são obtidos pelo somatório da nota máxima da questão multiplicada pelo seu peso (NUNES, 2010).

A título de exemplo, para a questão "A instituição faz campanhas de uso racional da energia elétrica?”, e em função da resposta do entrevistado, foi atribuído o valor de 3 pontos (numa escala variando de 0 a 5, conforme sugere o SICOGEA). A ele foi aplicado o peso 2 (dois), devido essa questão estar diretamente relacionada à A3P, o que totalizou 6 pontos. 0 ponto possível para tal questão era de 10 pontos (valor máximo da questão multiplicado pelo seu peso).

Após a obtenção dos resultados, é possível analisá-los conforme o índice geral de sustentabilidade encontrado, como apresentado no Quadro 3: 
Quadro 3 - Índice Geral de Sustentabilidade

\begin{tabular}{|l|l|l|}
\hline \multicolumn{1}{|c|}{ Resultado } & \multicolumn{1}{|c|}{ Sustentabilidade } & \multicolumn{1}{|c|}{ Desempenho: controle, incentivo, estratégia } \\
\hline Inferior a 20\% & Péssimo - "P” & $\begin{array}{l}\text { Grande impacto pode estar sendo causado ao meio } \\
\text { ambiente }\end{array}$ \\
\hline Entre 21 e 40\% & Fraco - "F" & $\begin{array}{l}\text { Pode estar causando danos, mas surgem algumas poucas } \\
\text { iniciativas }\end{array}$ \\
\hline Entre 41 e 60\% & Regular - "R" & Atende somente à legislação \\
\hline Entre 61 e 80\% & Bom - "B" & $\begin{array}{l}\text { Além da legislação, surgem alguns projetos e atitudes que } \\
\text { buscam valorizar o meio ambiente }\end{array}$ \\
\hline Superior a 80\% & Ótimo - "0" & $\begin{array}{l}\text { Alta valorização ambiental com produção ecológica e } \\
\text { prevenção da poluição }\end{array}$ \\
\hline
\end{tabular}

Fonte: Nunes (2010)

Com a obtenção do índice de sustentabilidade ambiental, pode-se verificar qual o comprometimento da instituição com a sociedade e o meio ambiente.

\section{RESULTADOS E DISCUSSÃ0}

A Tabela 1 mostra os resultados obtidos para cada área e seus respectivos critérios, bem como o resultado geral da avaliação de sustentabilidade na autarquia:

Tabela 1 - Avaliação de Sustentabilidade da autarquia estudada

\begin{tabular}{c|c|c|c|c}
\hline \multirow{2}{*}{ ÁREAS E CRITÉRIOS } & \multirow{2}{*}{ Pontos Possíveis a se atingir } & \multirow{2}{*}{ Pontos 0btidos } & \multicolumn{2}{|c}{ Sustentabilidade } \\
\cline { 3 - 5 } & & & Resultado & Avaliação \\
\hline Produção & 330 & 73 & $22,12 \%$ & Fraco \\
\hline Processos de Produção & 150 & 28 & $18,67 \%$ & Péssimo \\
\hline Fornecedores & 100 & 33 & $33,00 \%$ & Fraco \\
\hline Manutenção & 80 & 12 & $15,00 \%$ & Péssimo \\
\hline Recursos Humanos & 410 & 195 & $47,56 \%$ & Regular \\
\hline Equipe de Colaboradores & 190 & 91 & $47,89 \%$ & Regular \\
\hline Gestão da Instituição & 220 & 104 & $47,27 \%$ & Regular \\
\hline Marketing & 90 & 49 & $54,44 \%$ & Regular \\
\hline Responsabilidade Socioambiental & 90 & 49 & $54,44 \%$ & Regular \\
\hline Finanças & 110 & 89 & $80,91 \%$ & Ótimo \\
\hline Contabilidade Gerencial e Auditoria & 110 & 89 & $80,91 \%$ & Ótimo \\
\hline Total Geral & 940 & 406 & $43,19 \%$ & Regular \\
\hline
\end{tabular}

Fonte: Dados da pesquisa

Após a aplicação da lista de verificação proposta por Nunes (2010), os dados foram analisados e para a autarquia pesquisada obteve-se um índice de sustentabilidade ambiental geral de 43,19\%, valor considerado "regular". Ao aplicarem também o modelo SICOGEA em outros órgãos públicos, Souza e Pfitscher (2013) obtiveram o índice de 49,32\% e Barbosa (2014) 
Avaliação da sustentabilidade ambiental da sede administrativa de uma instituição federal - Rio de Janeiro, Brasil

obteve 47,95\%. Nota-se que esses órgãos públicos também se encontravam no mesmo patamar de desenvolvimento na questão da sustentabilidade que a autarquia estudada.

0 critério "Contabilidade Gerencial e Ambiental" foi aquele que obteve o melhor índice de sustentabilidade ambiental (80,91\%), sendo o único “ótimo” recebido pela instituição. Já o mais mal avaliado em relação a sua sustentabilidade ambiental foi 0 critério "Manutenção" $(15,00 \%)$, apresentando conceito "fraco".

0 critério "Processos de Produção" indica que a instituição não realiza campanhas de uso racional de combustível, de papel e demais materiais de consumo. 0 problema se mostra recorrente em órgãos públicos, uma vez que Souza e Pfitscher (2013), bem como Barbosa (2014), também constataram deficiências na gestão de resíduos sólidos em sua pesquisa.

0 órgão não utiliza papel reciclado e/ou não clorado, bem como a impressão de documentos no modo "frente e verso" não é o padrão. Além da adoção de tais medidas, recomendar-se-ia ainda o uso de "fontes ecológicas", que reduziriam o consumo de cartuchos de impressora. Outra medida que poderia ser adotada é o modelo de "ilhas de impressão", com uma impressora para diversos setores, o que facilitaria a fiscalização com relação a impressões pessoais que eventualmente possam estar ocorrendo no órgão. Sugere-se ainda a indicação de metas para fornecimento de papéis por setor, com a criação de um prêmio institucional para o setor que conseguisse atingir a maior redução relativamente ao ano anterior.

Em relação aos copos descartáveis, os mesmos são amplamente distribuídos pelo órgão. Sugere-se estabelecer a redução do fornecimento de copos descartáveis, distribuindo canecas reutilizáveis nos setores. Para eventuais visitantes, poderiam ser fornecidos copos de papel na copa, acabando o fornecimento de copos plásticos pelos corredores.

0 órgão utiliza como combustível para seus veículos apenas álcool e gasolina. Poderia ser realizada adaptação nos veículos de forma que pudessem utilizar ainda o gás natural veicular (GNV), o que reduziria os custos para o órgão, bem como a emissão de gases de estufa.

As lâmpadas instaladas no prédio são do tipo fluorescente. Recomenda-se a substituição gradual por lâmpadas de LED, mais econômicas. Não é plausível a substituição imediata, pois assim seria gerado um número grande de resíduos pelas lâmpadas fluorescentes e reatores eletrônicos. Dessa forma, é sugerido que a troca seja realizada na medida em que as lâmpadas atuais apresentem defeito, respeitando-se a vida útil das mesmas. Sugere-se ainda realizar estudos das instalações elétricas com o diagnóstico das perdas reais e de viabilidade para utilização de energia solar no prédio. 
Nos banheiros, percebe-se que a luz natural é suficiente para iluminá-lo durante o período diurno. Ainda assim, as luzes permanecem acesas durante todo o expediente. Sugerese a instalação de sensores de presença fotossensíveis nesses ambientes. Foi tentado ainda, no passado, restringir o uso do ar condicionado a um determinado horário, mas a tentativa foi frustrada, especialmente nos meses mais quentes do ano.

Em relação ao consumo de água, o órgão demonstra possuir controle. São realizadas três leituras diárias do hidrômetro visando rastrear possíveis vazamentos. As torneiras tiveram seus arejadores substituídos por dispersores econômicos. No prédio mais novo as descargas já são todas do tipo econômicas. Sugere-se a expansão desse tipo de descarga para o prédio antigo.

Apenas o prédio mais novo do órgão possui um sistema de captação água da chuva, que é direcionada para os tanques de lavagem. Recomenda-se a extensão do reaproveitamento de águas pluviais para o prédio antigo (o maior em área), aumentando o uso de águas cinzas na sede da autarquia.

Observa-se que a arquitetura dos prédios, aliada ao clima da região, não favorece a ventilação natural, o que faz que em boa parte do ano seja utilizado ar condicionado nos setores. A entrada de luz natural também não é suficiente para que as luzes artificiais possam ser apagadas durante o horário de expediente. 0 órgão ainda possui espaços que não atendem questões de acessibilidade. Aconselha-se que tais adaptações sejam efetuadas.

Os bens que não serão mais utilizados pela organização são basicamente divididos em dois grupos: recuperáveis e irrecuperáveis. Aqueles considerados recuperáveis são doados a outras instituições. Os bens irrecuperáveis são tratados como "lixo comum”, necessitando a instituição definir o método de armazenamento e disposição final adequados.

0 órgão ainda não possui um programa de coleta seletiva, o que contraria o Decreto $\mathrm{n}^{0}$ 5940/06 (BRASIL, 2006). Aconselha-se a imediata instituição de Comissão para tal fim e o contato com cooperativas e associações para realizarem o recolhimento dos resíduos recicláveis. Para o descarte dos papéis, sugerem-se caixas de armazenamento em cada setor, que posteriormente seriam coletados e transformados em blocos de anotações ou direcionados para cooperativas, a depender do estado do papel.

Os resíduos de construção são retirados em caçambas contratadas para esse fim. Recomenda-se que na próxima contratação a empresa responsável pela manutenção predial se encarregue também da destinação adequada desse tipo de resíduo. 
Avaliação da sustentabilidade ambiental da sede administrativa de uma instituição federal - Rio de Janeiro, Brasil

Os colaboradores da equipe de limpeza não foram capacitados para coletar e separar corretamente os resíduos, visto que o órgão não realiza a coleta seletiva. Faz-se necessário que os mesmos sejam capacitados para tal fim. 0 órgão não possui conhecimento exato do volume de resíduos gerados, dado que poderia resultar em melhorias à gestão ambiental, bem como no número de papéis higiênicos e toalhas de papel utilizadas diariamente.

0 critério "Fornecedores" apresentou um índice de sustentabilidade ambiental de 33,00\% (fraco), alcançado apenas 33 pontos dos 100 possíveis. Pela lista de verificação é possível perceber que não há preocupação com relação ao comportamento ambiental dos fornecedores. As poucas questões bem avaliadas são aquelas em que há exigência legal, como é o caso do Decreto no 5.450/2005 (BRASIL, 2005), que regulamentou o pregão eletrônico para aquisição de bens e serviços.

Há a necessidade dos órgãos incorporarem critérios sustentáveis em suas compras e contratações, de forma mais efetiva, fazendo seu papel de indutor do mercado no aumento da oferta de produtos e serviços sustentáveis. Outra ação a ser tomada é a inclusão nos instrumentos convocatórios da logística reversa para os resíduos sólidos gerados.

Pelo critério "Manutenção" é possível perceber que a escolha das empresas que realizam a manutenção predial e veicular não possui qualquer apelo ambiental, bem como a compra de materiais de limpeza. Sugere-se a revisão do processo de seleção dessas empresas prestadoras de serviços, a fim de que sejam priorizadas as que possuam maior apelo socioambiental. A autarquia ainda não monitora os níveis de poluição sonora, luminosidade, poluição do ar e ergonomia de equipamentos no ambiente interno.

No critério "Equipe de Colaboradores" obteve-se um índice de sustentabilidade ambiental de 47,27\%, observando-se ausência de ações de capacitação e conscientização dos servidores em relação a questões ambientais, de saúde e segurança do trabalho. Ainda que o órgão não possua uma política voltada para a gestão ambiental, nada impede que algumas atitudes sejam tomadas, como por exemplo: promoção de palestras, publicação de cartazes e comunicações internas. Campanhas com temáticas relacionadas ao uso racional do consumo de água, energia, papel e combustível, além favorecer o meio ambiente, poderiam reduzir as despesas do órgão.

Nas questões relacionadas à qualidade de vida, no que tange a segurança financeira de seus servidores, observa-se que boa parte das ações se baseia em legislações, tais como 0 pagamento de auxílio creche, auxílio alimentação e previdência privada, não sendo políticas 
oriundas da instituição. Uma ação do órgão que pode se ressaltar como positiva é a existência de um plano de saúde de gestão própria, exclusivo para funcionários do órgão.

É importante ainda que os servidores participem das ações de uso racional dos recursos naturais e bens públicos, bem como da gestão adequada dos resíduos sólidos, visto que tais atividades não devem ficar a cargo de alguns setores somente, mas devem contar com a participação de todos.

Dos servidores da autarquia, aproximadamente $28 \%$ possuem mestrado e $22 \%$ são doutores. 0 nível de capacitação dos funcionários impacta diretamente na remuneração, pois há uma retribuição por titulação, o que incentiva os servidores a se especializarem.

0 critério "Gestão da Instituição" foi considerado regular, obtendo um índice de 47,27\%. Para as questões não direcionadas diretamente para a área ambiental, a autarquia demonstrou ter certo controle. Porém em relação ao meio ambiente, a instituição carece de políticas que 0 relacionem à sua gestão. Além disso, o órgão não obteve nos últimos anos premiações ou reconhecimento pela sua atuação ambiental, não aplica recursos em projetos ambientais para sua sede, não possui um sistema de gestão ambiental implantado e nem possui um plano de qualidade ambiental. Como ponto positivo pode-se destacar os investimentos em pesquisas ambientais que ocorrem nos institutos subordinados ao órgão pesquisado, citados no planejamento estratégico da instituição.

A autarquia não possui em sua gestão institucional especialistas da área ambiental. Mesmo se tratando de um órgão público que não causa impactos expressivos ao meio ambiente, a figura de um profissional especializado nessa área poderia dar suporte à instituição quanto aos seus riscos ambientais. Além disso, tal profissional poderia contribuir na especificação para a aquisição de produtos e serviços mais sustentáveis. 0 órgão também não possui implantado nenhum Sistema de Gestão Ambiental, tampouco um plano de "qualidade ambiental".

0 critério "Responsabilidade Socioambiental" atingiu um índice de 54,44\%, conceito regular. É possível observar que é escassa a relação da autarquia com a sociedade, podendo ser melhorada. 0 fato de canais de relacionamento serem disponibilizados não é suficiente para que tal relação ocorra de forma veemente. Pode-se ressaltar ainda a importância de uma política de comunicação sobre a responsabilidade socioambiental, o que favoreceria a imagem da organização, visto que quando a relação com o meio ambiente é valorizada, sua imagem diante da opinião pública tende a se tornar diferenciada. 
Avaliação da sustentabilidade ambiental da sede administrativa de uma instituição federal - Rio de Janeiro, Brasil

No critério "Contabilidade Geral e Auditoria” foi obtido o único conceito "ótimo" da instituição, com um resultado de 80,91\%. Pelo questionário foi possível verificar que o órgão não sofreu multas nem pagou indenizações ambientais nos últimos anos. Como no critério “Gestão da Instituição”, pode-se afirmar que o setor responsável pela contabilidade possui uma gestão controlada de suas obrigações.

No geral, o índice de sustentabilidade calculado para a autarquia federal à luz do SICOGEA - geração 2 ficou em 43,19\%, considerado como "regular", mostrando que a instituição atende com uma parte de suas obrigações legais, o que pôde ser observado na prática, como iniciativas de coleta seletiva solidária, por exemplo, que não foram ainda implantadas pelo órgão.

\section{CONCLUSÃO}

Este estudo teve como objetivo avaliar a sustentabilidade na sede de uma autarquia federal à luz do SICOGEA - Geração 2, mais especificamente da primeira fase da terceira etapa do método (fase chamada "Investigação e Mensuração").

Por meio da coleta de dados da lista de verificação e sua análise, foi constatado um índice de sustentabilidade ambiental de 43,19\% para o órgão pesquisado, conceito considerado “regular”. Embora haja legislações que não estejam sendo cumpridas, algumas das ações existentes são oriundas da obrigação legal, o que vai ao encontro ao quesito "atende somente à legislação" da lista de verificação.

Foi possível perceber que o critério da área de "Finanças", "Contabilidade e Auditoria”, foi aquele que apresentou o melhor desempenho. Em contrapartida, os grupos relacionados à área de "Produção" foram os que mais contribuíram para a redução do desempenho da instituição, sendo eles: "Processos de Produção", "Fornecedores” e "Manutenção”.

Os resultados mostram a deficiência da gestão ambiental na organização, a qual deveria criar um setor especializado para implantá-la, conforme a proposta da Agenda Ambiental da Administração Pública (A3P), a fim de incentivar práticas mais sustentáveis que reduzam os possíveis impactos que possam estar sendo causados pelas suas atividades.

Uma das limitações do método SICOGEA é possibilitar a subjetividade do pesquisador, devido à falta de padronização da lista de verificação, bem como dificultar a comparação dos resultados entre instituições que atuam numa mesma atividade. Destaca-se ainda que os 
resultados apresentados nesta pesquisa se restringem ao órgão estudado, não podendo ser generalizados para as outras unidades do órgão, tampouco para demais organizações públicas.

Uma sugestão de melhoria ao SICOGEA seria criar listas de verificação padronizadas, já com pesos definidos para as questões, separados por atividade econômica. Dessa forma, acredita-se que a subjetividade do pesquisador seria minimizada e tornaria os resultados mais comparáveis. No caso do serviço público, a A3P poderia servir de referência para tais listas.

Para futuras pesquisas, sugere-se estender a lista de verificação aplicada nesta pesquisa a outros momentos, a fim de traçar uma evolução da sustentabilidade ambiental na autarquia à luz do SICOGEA - Geração 2. Pode-se ainda aplicar o método em outros órgãos públicos que desenvolvam atividades similares ao caso estudado, a fim de comparar os resultados obtidos.

\section{REFERÊNCIAS BIBLIOGRÁFICAS}

BARBOSA, N. M. Análise da sustentabilidade ambiental na Justiça Federal do Amazonas: estudo de caso usando um Sistema Contábil Gerencial Ambiental. Manaus. 2014. Dissertação (Mestrado em Contabilidade e Controladoria) Universidade Federal do Amazonas, Manaus.

BOCA SANTA, S. L. Avaliação de edifícios sustentáveis em instituições de ensino superior públicas federais: proposição de um modelo baseado em sistemas gerenciais de avaliação socioambiental. 2017. Dissertação (Mestrado em Contabilidade) - Universidade Federal de Santa Catarina, Florianópolis.

BÖHRINGER, C.; JOCHEM, P. E. P. Measuring the immeasurable - A survey of sustainability indices. Ecological Economics, [s.l.], v. 63, n. 1, p. 1-8, 2007.

BRASIL. Agenda Ambiental na Administração Pública. Brasília: MMA, 2009.

BRASIL. Constituição da República Federativa do Brasil de 1988. Brasília, 5 out 1988.

BRASIL. Construções Sustentáveis. MMA, 2018. Disponível em: http://www.mma.gov.br/component/k2/item/10317eixos-temáticos-construções-sustentáveis. Acesso em 17 mar 2018.

BRASIL. Decreto $\mathrm{n}^{\circ} \mathbf{7 . 7 4 6}$ de 5 de junho de 2012. Regulamenta o art. $3^{\circ}$ da Lei $\mathrm{n}^{\circ} 8.666$, de 21 de junho de 1993, para estabelecer critérios e práticas para a promoção do desenvolvimento nacional sustentável nas contratações realizadas pela administração pública federal direta, autárquica e fundacional e pelas empresas estatais dependentes, e institui a Comissão Interministerial de Sustentabilidade na Administração Pública - CISAP. Brasília, 6 jun 2012.

BRASIL. Decreto $\mathrm{n}^{0} 5.450$ de 31 de maio de 2005. Regulamenta o pregão, na forma eletrônica, para aquisição de bens e serviços comuns, e dá outras providências. Brasília, 1 jun 2005.

BRASIL. Decreto n 5.940 de 25 de outubro de 2006. Institui a separação dos resíduos recicláveis descartados pelos órgãos e entidades da administração pública federal direta e indireta, na fonte geradora, e a sua destinação às associações e cooperativas dos catadores de materiais recicláveis, e dá outras providências. Brasília, 26 out 2006.

CHAVES, L. C.; FREITAS, C. L. DE; ENSSLIN, L.; PFITSCHER, E. D.; PETRI, S. M.; ENSSLIN, S. R. Gestão ambiental e sustentabilidade em instituições de ensino superior: construção de conhecimento sobre o tema. Revista Gestão Universitária na América Latina - Gual, Florianópolis v.6, n.2, p. 33-54, 2013. 
Avaliação da sustentabilidade ambiental da sede administrativa de uma instituição federal - Rio de Janeiro, Brasil

DEEGAN, C. Introduction: The legitimising effect of social and environmental disclosures - a theoretical foundation. Accounting, Auditing \& Accountability Journal, [s.l.], v.15, n.3, p.282-311, 2002.

FREITAS, C. L. Avaliação de sustentabilidade em instituições públicas federais de ensino superior (IFES): proposição de um modelo baseado em sistemas gerenciais de avaliação e evidenciação socioambiental. 2013. Dissertação (Mestrado em Contabilidade) - Universidade Federal de Santa Catarina, Florianópolis.

GUTHRIE, J.; PARKER, L D. Corporate Social Reporting: A Rebuttal of Legitimacy Theory. Accounting and Business Research, [s.l.], v.19, n.76, p. 343-352, 1989.

LERÍPIO, A. A. GAIA: um método de gerenciamento de aspectos e impactos ambientais. 2001. Tese (Doutorado em Engenharia de Produção) - Universidade Federal de Santa Catarina, Florianópolis.

MARTINS, E; DE LUCA, M. M. M. Ecologia via contabilidade. Revista Brasileira de Contabilidade, Brasilia, v. 23, n. 86, p. 20-33, 1994.

MMA. Portaria $\mathrm{n}^{0} 3$ de 27 de fevereiro de 2018. Institui as diretrizes do Programa da Agenda Ambiental na Administração Pública - Programa A3P. Brasília, 01 mar 2018.

MPOG. Instrução Normativa $\mathbf{n}^{\circ} 01$ de 19 de janeiro de 2010. Dispõe sobre os critérios de sustentabilidade ambiental na aquisição de bens, contratação de serviços ou obras pela Administração Pública Federal direta, autárquica e fundacional e dá outras providências. Brasília, 27 jul 2010.

NUNES, J. P. 0. Um aporte ao sistema contábil gerencial ambiental: elaboração e aplicação parcial do novo sistema em clínica hospitalar. 2010. Dissertação (Mestrado em Contabilidade) - Universidade Federal de Santa Catarina, Florianópolis.

PFITSCHER, E. D. Gestão e sustentabilidade através da contabilidade e controladoria ambiental: estudo de caso na cadeia produtiva de arroz ecológico. 2004. Tese (Doutorado em Engenharia de Produção) - Universidade Federal de Santa Catarina, Florianópolis.

SANTOS, A. R. Metodologia Científica: A construção do conhecimento. 8 ed. Rio de Janeiro: Lamparina, 2015.

SANTOS, A. 0.; SILVA, F. B.; SOUZA, S.; SOUSA, M. F. R. Contabilidade Ambiental: Um Estudo sobre sua Aplicabilidade em Empresas Brasileiras. Revista Contabilidade \& Finanças, São Paulo, v.16, n. 27, p. 89-99, 2001.

SILVA, P. L. M. Desenvolvimento sustentável e suas contradições. Revista Internacional de Ciências, Rio de Janeiro, v.4, n.2, p.107-119, 2014.

SOUZA, P.; PFITSCHER, E. D. Gestão e sustentabilidade ambiental: estudo em um órgão público do estado de Santa Catarina. Revista de Contabilidade e Controladoria, Curitiba, v.5, n.3, p.8-32, 2013.

SOUZA, V. D.; UHLMANN, V. 0.; PFITSCHER, E. D. Sustentabilidade ambiental em instituição de ensino: Aderência à Agenda Ambiental de Administração Pública. Revista Perspectivas Contemporâneas, Campo Mourão, v.10, n.l, p.l26$145,2015$.

TAUCHEN, J.; BRANDLI, L. L. A gestão ambiental em Instituições de Ensino Superior: Modelo para Implantação em Campus Universitário. Gestão \& Produção, São Carlos, v.13, n.3, p.503-515, 2006.

UHLMANN, V. 0. Contribuições ao desenvolvimento do Sistema Contábil Gerencial Ambiental - geração 2: proposição da terceira geração do método. 2011. Dissertação (Mestrado em Contabilidade) - Universidade Federal de Santa Catarina, Florianópolis.

VIEIRA, I. L.; SILVA, E. R. Análise da aderência de uma autarquia federal aos eixos da A3P - Rio de Janeiro/RJ. In: CONGRESSO INTERNACIONAL DE TECNOLOGIAS PARA 0 MEIO AMBIENTE, 6. Bento Gonçalves, 2018. 